\title{
A relevância de ações educativas na conscientização do câncer de colo uterino
}

The relevance of educational actions in the awareness of cervical cancer

La relevancia de las acciones educativas en la concientización del cáncer cervicouterino

Ana Karina Rodrigues Coelho

ORCID: https://orcid.org/0000-0001-8504-689X

Centro Universitário Fibra, Brasil

E-mail: anna.karinna1999@gmail.com

Tamires Costa Franco

ORCID: https://orcid.org/0000-0002-8978-4176

Universidade da Amazônia, Brasil

E-mail:tamiresfranco98@gmail.com

Amanda Almeida Vieira

ORCID: https://orcid.org/0000-0003-2211-0115

Centro Universitário do Estado do Pará, Brasil

E-mail: amandaav2000@gmail.com

Marcelo De Jesus Calandrini de Azevedo Junior

ORCID: https://orcid.org/0000-0001-9916-7668

Centro Universitário Fibra, Brasil

E-mail: marcelinho.j.jr@gmail.com

Isis Batista de Oliveira

ORCID: https://orcid.org/0000-0002-5783-8686 Centro Universitário do Estado do Pará, Brasil

E-mail: isisbatista77@gmail.com

Manuelle Pinto Sotero

ORCID: https://orcid.org/0000-0002-6798-4572

Centro Universitário do Estado do Pará, Brasil

E-mail: adv.manuelle@gmail.com

Maria Clara Arêa Leão Martins

ORCID: https://orcid.org/0000-0002-9804-7717

Centro Universitário do Estado do Pará, Brasil

E-mail: arealeaomartins.mariaclara@gmail.com

Ana Carolina Da Silva Borges

ORCID: https://orcid.org/0000-0003-2454-331X

Escola Superior da Amazônia, Brasil E-mail: a.sborges20@gmail.com

Lorena Barros Bahia

ORCID: https://orcid.org/0000-0003-4444-3850

Centro Universitário do Estado do Pará, Brasil

E-mail: lorenabbahia@gmail.com

Ana Letícia de Mello Lobato

ORCID: https://orcid.org/my-orcid?orcid=0000-0003-0389-4276

Centro Universitário do Estado do Pará, Brasil

E-mail: analeticiamlobato@gmail.com

\begin{abstract}
Resumo
O câncer do colo do útero é a doença mais frequentemente relacionada ao Papilomavírus Humano (HPV). O câncer cervical é caracterizado por uma multiplicação das células e podem atingir tecidos próximos e até mesmo os mais distantes. A infecção por HPV associada a outros fatores de risco, como história de outras doenças sexualmente transmissíveis, tabagismo e uso de contraceptivo oral, representa importante papel na progressão das lesões escamosas intraepiteliais para a malignidade em mulheres brasileiras. O objetivo é relatar a experiência acadêmica diante de uma conscientização educativa sobre a importância da realização do exame preventivo, a partir de uma roda de conversa interativa em uma Unidade Municipal de Saúde (UMS), localizada em Belém no Estado do Pará. Esta pesquisa tratase de um relato de experiência, de abordagem qualitativa, realizada com mulheres que aguardavam a consulta para realização do exame preventivo. Como componente da equipe multiprofissional na atenção básica cabe as profissionais de saúde promoverem ações educativas a fim de proporcionar conhecimentos e esclarecer dúvidas sobre a temática proposta. Com base na dinâmica proposta, notou-se a importância de informação sobre realizar o exame preventivo para detecção precoce do câncer do colo do útero.
\end{abstract}

Palavra-chave: Conscientização; Mulheres; Útero. 


\begin{abstract}
Cervical cancer is the disease most often related to Human Papillomavirus (HPV). Cervical cancer is characterized by a multiplication of cells and can reach nearby and even distant tissues. HPV infection associated with other risk factors, such as a history of other sexually transmitted diseases, smoking and use of oral contraceptives, plays an important role in the progression of squamous intraepithelial lesions to malignancy in Brazilian women. The objective is to report the academic experience in the face of an educational awareness about the importance of carrying out the preventive examination, from an interactive conversation circle in a Municipal Health Unit (UMS), located in Belém in the State of Pará. It is an experience report, with a qualitative approach, carried out with women who were waiting for the consultation to carry out the preventive examination. As a component of the multidisciplinary team in primary care, health professionals are responsible for promoting educational actions in order to provide knowledge and clarify doubts about the proposed theme. Based on the proposed dynamics, it was noted the importance of information about performing the preventive examination for early detection of cervical cancer.
\end{abstract}

Keywords: Awareness; Women; Uterus.

\title{
Resumen
}

El cáncer de cuello uterino es la enfermedad más frecuentemente relacionada con el Virus del Papiloma Humano (VPH). El cáncer de cuello uterino se caracteriza por una multiplicación de células y puede llegar a tejidos cercanos e incluso distantes. La infección por VPH asociada a otros factores de riesgo, como antecedentes de otras enfermedades de transmisión sexual, tabaquismo y uso de anticonceptivos orales, juega un papel importante en la progresión de lesiones intraepiteliales escamosas a malignidad en mujeres brasileñas. El objetivo es relatar la experiencia académica frente a una conciencia educativa sobre la importancia de la realización del examen preventivo, a partir de una rueda de conversación interactiva en una Unidad Municipal de Salud (UMS), ubicada en Belém en el Estado de Pará. Relato de experiencia, con abordaje cualitativo, realizado con mujeres que esperaban la consulta para realizar el examen preventivo. Como componente del equipo multidisciplinario en la atención primaria, los profesionales de la salud son responsables de promover acciones educativas con el fin de proporcionar conocimientos y aclarar dudas sobre el tema propuesto. Con base en la dinámica propuesta, se destacó la importancia de la información sobre la realización del examen preventivo para la detección temprana del cáncer de cuello uterino.

Palabras clave: Conciencia; Mujer; Útero.

\section{Introdução}

O câncer de colo de útero, também chamado de câncer cervical, é causado pela infecção persistente por alguns tipos do papiloma vírus humanos (HPV). Em alguns casos, ocorrem alterações celulares que podem evoluir para o câncer (Câncer, 2021).

O câncer cervical é caracterizado por uma multiplicação desordenada das células que ocorre na porção inferior do útero, podendo atingir tecidos próximos e até mesmo os mais diante. Na maioria dos casos é assintomático, porém pode causar sangramento vaginal durante relações sexuais, corrimento de cor escura e com mau odor, e nos estagio avançados pode causar hemorragia, obstrução de vias urinarias e intestinais (Silva et al.,2020).

O câncer uterino é um problema de saúde pública com aproximadamente 570 mil casos e 311 mil mortes pelo mundo (Claro et al., 2021). De acordo com o INCA (2019) o câncer de colo de útero é o segundo tipo de neoplasia maligna que mais atinge mulheres no mundo, e o climatério é a faixa etária com maior número de casos, tendo uma maior propensão ao aparecimento das neoplasias.

A infecção por HPV associada a outros fatores de risco, como história de outras doenças sexualmente transmissíveis, tabagismo e uso de contraceptivo oral, representa importante papel na progressão das lesões escamosas intraepiteliais para a malignidade em mulheres brasileiras (Guimarães, 2019).

Segundo o INCA (2019) é no climatério que as mulheres começam a realizar a terapia de reposição hormonal devido a diminuição dos hormônios, o que aumenta o risco de surgimento do câncer cervical, a idade também é um fator importante, pois ocorre uma frequência maior de câncer do colo do útero.

O rastreamento é realizado com o exame citopatológico que contribui para a redução das taxas de incidência e mortalidade da doença (Tallon et al.,2020). O exame citopatológico é oferecido pelo Sistema Único de Saúde (SUS), como 
parte da Atenção Primária à Saúde (APS) e das políticas de saúde da mulher, para realizar o rastreamento, o diagnóstico e o tratamento do câncer de colo uterino (Santos et al.,2019).

$\mathrm{O}$ método de rastreamento deve ser oferecido às mulheres ou qualquer pessoa com colo do útero, na faixa etária de 25 a 64 anos e que já tiveram atividade sexual. A priorização desta faixa etária como a população alvo, justifica por ser a de maior ocorrência das lesões de alto grau, passíveis de serem tratadas efetivamente para não evoluírem para o câncer (INCA, 2021).

A coleta do exame é realizada durante uma consulta ginecológica de rotina, após a introdução do espéculo vaginal, sem ou com colocação de nenhum lubrificante. Normalmente não é doloroso, mas um desconforto variável pode acontecer, de acordo com a sensibilidade individual de cada paciente. As mulheres devem ser previamente orientadas a não terem relações sexuais ou fazerem uso de duchas, medicamentos ou exames intravaginais durante as 48 horas que precedem o exame a fim de garantir a eficácia dos resultados (Casarin e Piccoli, 2011).

O exame preventivo Papanicolau é um método para identificação e prevenção da infecção do HPV e do desenvolvimento do câncer do colo do útero, onde é realizado de forma que se identifica alteração celular, antes mesmo que a infecção apresente sintomas, como verrugas genitais ou feridas no colo do útero e sangramentos repentinos acompanhados de dor. (Brasil,2015).

A atitude preventiva e a educação em saúde para o cuidado e melhoria da qualidade de vida das mulheres são um importante componente para a detecção precoce da infecção pelo papiloma vírus humano e também para a detecção do câncer de colo do útero. Na atenção primaria existe toda uma sistematização para rastreamento e detecção do câncer de colo de útero ressaltando os benefícios da realização do Papanicolau, juntamente com a educação dos profissionais e da população (Ramos et al.,2015).

A atenção básica em saúde tem o propósito de realizar ações para a promoção e proteção da saúde da população em geral, através de suas ações, busca prevenir, orientar e informar a respeito da patologia, incentivando a realização do exame Papanicolau, sendo considerado o mais efetivo e eficiente a ser aplicado coletivamente em programas de rastreamento (Peixoto et al.,2020)

A incidência de câncer do colo de útero pode ser reduzida a partir de políticas que visem o monitoramento da doença, baseando-se em sua ocorrência natural e no reconhecimento de que câncer invasivo evolui a partir de lesões precursoras, ou seja, lesões intraepiteliais escamosas de alto grau e adenocarcinoma in situ, que podem ser detectadas e tratadas adequadamente, impedindo a progressão da doença (Maia et al.,2017)

\section{Metodologia}

Este estudo é caracterizado como descritivo do tipo relato de experiência, realizado em uma Unidade de Saúde no estado do Pará.

Na referida UBS, ocorreu a conscientização para realização do câncer uterino. Com o auxílio de profissionais de saúde que já trabalham na área, ocorreu uma roda de conversa para mulheres que aguardavam a realização do exame preventivo, junto com a equipe multiprofissional, a fim de sanar todas as dúvidas relacionadas ao exame e ao câncer de colo de útero.

Antes de iniciar os atendimentos foi planejado e executado uma ação educativa que visasse a conscientização para aquelas mulheres que aguardavam a coleta do preventivo, afim de esclarecer dúvidas e questionamentos sobre o tema que foi abordado. 
O esclarecimento do tema foi feito em uma linguagem acessível de forma objetiva, onde foi utilizado um banner de apoio oferecido pela unidade, para informar para aquelas mulheres sobre a importância da realização do exame e de que modo era realizado o procedimento, uma vez que algumas mulheres sentem vergonha, o que acaba dificultando a coleta.

A realização do bate papo que visou informa-las sobre a importância da coleta ocorre na sala de coleta, apenas com as mulheres que compareceram para realizar o exame. A partir da conversa que ocorreu de maneira clara e esclarecedora, notouse que todas presentes atentaram-se no assunto que estava sendo discutido.

Foi um momento que a equipe buscou a participação de todas as mulheres, buscando incentiva-las a participar da roda de conversa proposta, para que pudesse ser esclarecidas duvidas e curiosidades acerca do assunto.

A base teórica transcorreu pela busca bibliográfica em bases científicos digitais, sendo estes: Scientific Eletronic Library Online (SCIELO) e Biblioteca Virtual em Saúde (BVS), com a utilização de palavras chaves identificadas nos Descritores em Ciência da Saúde (DeCS).

\section{Resultados e Discussão}

A equipe multiprofissional é fundamental na atenção básica para auxiliar na prevenção e tratamento do câncer de útero. Foi abordado sobre o enfrentamento desde o diagnóstico do CA de útero até uma possível cirurgia.

A saúde é uma ciência que tem como principal objetivo, o cuidado. Nesse ponto de vista o enfoque preventivo, assim como a promoção da saúde, deve nortear a prática assistencial. (Soares \& Heidemann, 2019). De acordo com o INCA (2021) o objetivo da atenção primária é impedir que o câncer se desenvolva, o que inclui evitar a exposição a fatores de risco e a adoção de uma vida saudável.

Diante a pesquisa prática e teórica, notou-se a falta de diálogo na atenção primária em relação à prevenção, diagnóstico e tratamento, e certos tabus diante um exame simples. É essencial promover educação em saúde, principalmente na atenção primária, onde podemos vivenciar experiências, além de proporcionar uma escuta à essa mulher, a fim de motivá-la a realizar o exame sem medo, e a enfrentar a doença em casos de resultados positivos.

Desta forma, as informações de práticas de autocuidado contribuem para a efetivação do processo de educação em saúde, possibilitando o incentivo de hábitos de vida mais saudáveis, desestimulando aos poucos hábitos inadequados e contemplando a necessidade de cada pessoa (Costa et al.,2020).

No entanto, de acordo com as ações educativas voltadas para conscientização, o intuito é atingir um número alto de mulheres para realização deste exame importante para sua saúde, além de elucidar os fatores de risco como má alimentação, sedentarismo, alcoolismo, entre outros que podem ser prejudiciais e ser predisponentes a canceres.

Durante a conversa foi abordado sobre os sinais e sintomas, para que essas mulheres ficassem atentas a qualquer tipo de secreção vaginal, para que assim possam buscar ajuda de um profissional de saúde para que o caso seja investigado.

Vale reforçar que o Sistema Único de Saúde (SUS) oferece o exame preventivo de forma gratuita, para mulheres na faixa etária de 25 a 64 anos, e as quais já tiveram atividade sexual, além de fornecer métodos contraceptivos para que não haja progressão da doença.

Destaca-se por fim o desempenho acadêmico que aproxima o profissional do paciente por meio de didáticas e práticas de forma criativas, para obter como finalidade o esclarecimento de dúvidas e obtenção de conhecimentos.

\section{Conclusão}

Completamos este trabalho elucidando a importância da abordagem deste tema na atenção primária de saúde, que é porta aberta para deteç̧ão de diversas doenças. Sendo a conscientização educativa necessária para informar de forma simples e objetiva sobre o câncer uterino. 
Research, Society and Development, v. 11, n. 2, e32011225840, 2022

(CC BY 4.0) | ISSN 2525-3409 | DOI: http://dx.doi.org/10.33448/rsd-v11i2.25840

O estudo teve como objetivo relatar uma experiência em educação em saúde remetendo reflexões e intervenções para o conhecimento. Destacando a união das diversas áreas de saúde para a promoção da conscientização voltada para comunidade, sendo uma estratégia para melhorar a adesão de exames e tratamentos.

Espera-se que sejam adicionadas novas atividades em conscientização a este tema, no contexto de atenção primaria, além de mais estudos, pois assuntos como estes relatando passo a passo sobre exame de saúde são fundamentais para o engajamento e adesão do público.

\section{Referências}

Brasil. (2015). Ministério da saúde. Biblioteca virtual em saúde. Papanicolau (exame preventivo de colo de útero). Set. https://bvsms.saude.gov.br/dicas-emsaude/2069-papanicolau-exame-preventivo-de-colo-de-utero

Casarin, M. R., \& Piccoli, J. d. C. E. (2011). Educação em Saúde para Prevenção do Câncer de Colo do Útero em Mulheres do Município de Santo Ângelo/RS., 1-8.

Claro , I. B. Lima, L. D. d., Patty Fidelis de Almeida, P. F. d. (2021). Diretrizes, estratégias de prevenção e rastreamento do câncer do colo do útero: as experiências do Brasil e do Chile. 1-14.

Costa, P.V.D., Silva, J. M. L., Silva, L. C. Rocha, S. G., Costa, L. F., Soares, M. K. M., Santos, S. R. P., Lima, P. C., Rodrigues, B. N. B., Almeida, M. S.,Soeiro, J. S., Martins, L. Santos, G. L., A. C. S., \& Tavares, I. I. S. (2020). A educação em saúde como ferramenta no combate ao câncer de mama: relato de experiência. Research, Society and Development, 9(10).

Guimarães, R. F. (2019). Câncer de colo do útero: abordagem teórica sobre avanços da doença, prevenção e controle., 1-35.

INCA, Instituto Nacional do Câncer, Ministério da Saúde. Câncer do colo do útero, 2019.

INCA, Ministério da Saúde. Câncer do colo do útero, 2021.

INCA, Ministério da saúde. Conceito e Magnitude. 2021.

INCA, Ministério da Saúde. Detecção precoce, 2021.

Maia, s. m. d. A., Jardim, C. F., Moraes, C. C. d. S., Scotelario, D. G. Correia, G. B. d. S., \& Silva, L. M. d. S. (2017). O enfermeiro na prática do exame citopatológico de colo do útero: relato de experiência. 1-5.

Peixoto, H. d. A., Spindola, T., Moerbeck, N. d. S. T., Motta, C. V. V. d., Soares, B. G. d. S., Barros, L. M. C. d., \& Abreu, T. d. O. (2020). Adesão de mulheres ao exame papanicolau: uma revisão integrativa. 1-13 Hugo de Andrade Peixoto.

Ramos de Souza, K,et al. (2015). Educação popular como instrumento participativo para a prevenção do câncer ginecológico: Percepção de mulheres.

Santos, T. L. d. S., Silveira, M. B., \& Rezende, H. H. A. (2019). A importância do exame citopatológico na prevenção do câncer do colo uterino. 1-15.

Silva, M. L. Nunes, J. S. S. Oliveira, K. S. d., \& Leite, T. A. S. (2020). Conhecimento de mulheres sobre câncer de colo do útero: Uma revisão integrativa. 113.

Soares, C. F., \& Heidemann, I. T. S. B. (2019). Promoção Da Saúde E Prevenção Da Lesão Por Pressão: Expectativas Do Enfermeiro Da Atenção Primária. 19.

Tallon, B., Monteiro, D., Soares, L., Rodrigues, N., \& Morgado, F. (2020). Tendências da mortalidade por câncer de colo no Brasil em 5 anos (2012-2016)., 110 . 